\title{
Treatment evidence approach of Bell's palsy: A review article (What we need to know?)
}

\author{
Ahmed Hisham Nasr ${ }^{1}$ and Yousif I Eltohami ${ }^{2 *}$ \\ ${ }^{1}$ Resident of oral and maxillofacial surgery, University of Medical Sciences and Technology, Khartoum Sudan \\ ${ }^{2}$ Assistant professor of oral and maxillofacial surgery, Faculty of dentistry, University of khartoum, Sudan
}

Submission: June 22, 2020; Published: July 02, 2020

*Corresponding author: Yousif Idris Eltohami, Assistant professor of oral and maxillofacial surgery, faculty of dentistry, University of khartoum, Sudan

\begin{abstract}
Acute idiopathic lower motor neuron facial paralysis is a condition that paralyzes the facial nerve and causes weakness of the face on the ipsilateral side, it's the most common cause of facial nerve paralysis with a female predilection with a mean age of 17 to 30 it accounts for 11 40 cases out of each 100,000 around the world. Bell's palsy may lead to serious complications which contain motor synkinesis crocodile tears, incomplete recovery, contracture of facial muscles, loss of taste and problems with dysarthria due to facial muscle weakness Management of Bell 's palsy is controversial since $70 \%$ of patients will recover normal function without treatment nevertheless the main goals of treatment are to enhance the recovery and prevent eye complications which occur to inability of eye closure. Eye care includes lubrication and eye patching, there are several treatment modalities of Bell's palsy which include use of corticosteroids, antiviral agents, a combination of antiviral and corticosteroids and non-drug, combination of drugs or non-drug therapies.
\end{abstract}

Keywords: Bell's palsy; Treatment evidence; Facial nerve; Corticosteroids; Antivirals

\section{Introduction}

Bell's palsy is a condition that paralyzes the facial nerve, which is the seventh cranial nerve. It's usually unilateral acute in onset and could be either partial or complete. It's the most common cause of facial nerve paralysis with a female predilection with a mean age of 17 to 30 it accounts for 11-40 cases out of each 100,000 around the world [1]. It presents as a sudden onset of unilateral peripheral facial weakness and can be diagnosed without difficulty in patients with isolated facial weakness of unknown origin. Other symptoms include, pain posterior to or in the ear, numbness and tingling of the ipsilateral side of the face, disturbed taste sensation of the anterior one third of the tongue. The underlying cause seen in post-mortem cases is vascular dilation, inflammation and edema with ischemia of the facial nerve, but the cause is still unclear [2] bell's palsy is more prevalent among females ages 21 to 40 , more commonly affecting the right side of the face and usually during the winter time [3].

\section{Clinical presentation}

There are several symptoms and signs of Bell's palsy that can vary from mild to severe. Signs of Bell 's palsy may include absence of forehead wrinkling, droopy eyelid, dry eye or excessive tearing, drooping corner of the mouth, dry mouth and impaired taste as well as facial paralysis and weakness. Difficulty with eating due to impaired muscle control on the ipsilateral side. There are other conditions to consider in the differential diagnosis like upper motor neuron lesion, based on innervations absence of forehead wrinkling is a good way to distinguish between them [4]. Herpes zoster oticus (ramsay hunt syndrome) and even rarer causes may include otitis media, HIV infection, sarcoidosis, autoimmune disorders or tumors of the parotid and Lyme disease [5]. Bell's palsy may lead to serious complications which contain motor synkinesis ( involuntary movement occurring at the same time as voluntary), crocodile tears, incomplete recovery, contracture of facial muscles, loss of taste, problems with dysarthria due to facial muscle weakness $[4,5]$.

\section{Diagnostic workup}

Although the diagnosis of bells palsy is purely clinical, there are some diagnostic tests done 14 days from the onset that can give information about the prognosis. The nerve excitation test recording the minimum electrical stimulus needed to give visible muscle contraction determines the excitation threshold. A $3.5 \mathrm{~mA}$ difference between healthy side and side of weakness is considered to be of inferior outcome [5]. The only test currently 
available to test the intracranial pathway of the facial nerve is the trigeminal blink reflex and is also helpful to assess possible complications like synkinesis and hemifacial spasms [6].

\section{Prognosis}

The symptoms of bell's palsy usually vary in severity from severe paralysis to mild symptoms, but the prognosis Is generally good. $71 \%$ of patients recover normal function without treatment, $13 \%$ are left with slight weakness and around $4 \%$ with severe weakness. Contracture of the facial muscles of expression was found in $17 \%$ and synkinesis in $16 \%$ [7]. Recurrence rate of $7 \%$ was noted with similar recurrence of both same side and opposite side [8]. Indicators of poor prognosis include old age, hypertension. Diabetes mellitus, taste impairment and complete facial weakness. The two most common abnormal healing patterns are crocodile tears (lacrimation of ipsilateral eye during chewing) and jaw winking (closure of the ipsilateral eyelid when jaw opens) [9].

\section{Management}

The main goals of treatment are to enhance the recovery and prevent eye complications which occur due to inability of eye closure. Eye care includes lubrication and eye patching, lubricating drops such as hypromellose should be used during the day and an eye ointment should be used at night. In severe cases the eye may have to be partially sutured closed or taped [10]. There are several treatment modalities for Bell's palsy which include, use of corticosteroids, antiviral agents, a combination of antiviral and corticosteroids and non-drug therapy, combination of drugs and non-drug therapies. Corticosteroids are used in the acute phase of bell's palsy under the assumption that inflammation and edema of the facial nerve are involved in causing bell's palsy. Their potent anti-inflammatory effect decreases nerve injury and improves the prognosis. Their maximum benefit is seen within 72 hours of the onset of the disease. There is no optimum dose but a dose of 50-60mg prednisolone daily in adults is commonly used. It's used at a regimen of $1 \mathrm{mg} / \mathrm{kg} /$ day to a maximum of $80 \mathrm{mg}$ [11]. In randomized clinical trials the rate of recovery at nine months with prednisolone was $94 \%$ and $81 \%$ for patients who didn't receive it [12].

As shown by systemic review of clinical trials $17 \%$ of patients taking prednisolone within six months had incomplete recovery compared with $28 \%$ of patients who received no treatment. A reduction of motor synkinesis was also shown, but there was no significant decrease in contracture of facial muscles [13]. Randomized double blind placebo trails have shown gripping evidence that corticosteroid improves patient outcome and speed up recovery time. Prednisolone should be used in all patients with Bell's palsy of less than $72 \mathrm{hr}$ duration who do not have a contraindication for its use [14]. In a study by yabing dong et al about steroid-antiviral treatment versus steroids alone for the treatment of bell's palsy, it was concluded that there was a significant difference and that the steroid-antivirals combination achieves a greater recovery rate [15]. A study was done to compare conservative therapy and steroid therapy for bell's palsy in children by hye woo yoo et al and showed that children with bell's palsy showed good prognosis with or without corticosteroids treatment and that there is no difference in prognosis [16]. In a systemic review and meta-analysis about corticosteroids versus corticosteroids plus antiviral agents in the treatment of bell's palsy by John K. Goudakos concluded that the addition of antiviral agent for the treatment is not associated with an increased rate of recovery [17].

In 2012 a systemic review to determine whether children benefit from steroid treatment by Jacob pitaro et al showed that there is a lack of evidence and therefore the role of corticosteroids in children remains inconclusive [18]. In 2000 a meta-analysis to determine the effectiveness of corticosteroids for idiopathic facial nerve paralysis by Mitchell Jay Ramsey showed better outcome for individuals with bell's palsy and that steroids improve the incidence of recovery by $17 \%$ [19]. Prednisolone should be used with caution in immunosuppression and infections it may trigger or excacebrate peptic ulcer disease, hyperglycemia especially in diabetics, malignant hypertension, renal and hepatic malfunction [4]. Antiviral agents are used under the rationale that inflammation of the facial nerve of bell's palsy is due to viral origin and might be related to the herpes simplex virus. Latent HSV type1 has been isolated from most of geniculate gangilion samples in an autopsy study [20]. The HSV-1 genome was detected in 79\% of facial nerve endoneurial fluid in patients with the disease but not in the controls [21]. The antiviral agents used in trials were acyclovir $400 \mathrm{mg}$ five times daily for five days or valaciclovir $1000 \mathrm{mg} /$ day in five-day duration. However, the use of of anitvirals as single agents or in combination with corticosteroids has not been definitely established. There no evidence for the use of either antiviral drug on its own and there is doubt regarding their use along with corticosteroids [22,23].

\section{Combination Therapy}

Randomized clinical trials found that at nine months from diagnosis, function had recovered in $94.4 \%$ of patients who took prednisolone alone. $85.4 \%$ who took antiviral agents alone. $92.7 \%$ who received a combination of both. This concluded that early treatment with prednisolone alone increases chances of complete recovery and there's no added benefit of antiviral agents alone or in combination [8]. Although a systemic review revealed that steroids decreases the chances of complete recovery but using an antiviral agent had an increase benefit [24]. A randomized prospective study established that combination therapy was more effective in treating severe to complete Bell's palsy than steroid alone [25]. A guideline development group deduced that there was low quality proof of benefit from adding antivirals and patients who were given them should be counseled that the increase in recovery is less than 7\% [26]. Adverse effects of antiviral drugs may include, vomiting and nausea, diarrhea, neurological deficits, abdominal pain, hepatitis and jaundice very rarely [27]. 


\section{Non-Drug Therapy}

Various physical therapies, such as exercise, biofeedback, laser, electrotherapy, massage, and thermotherapy are all used to speed up recovery. However, there is no evidence of improved benefit. A Cochrane review deduced poor quality evidence that facial exercises can help improve facial function, mainly for moderate paralysis and chronic cases. However, the possibility that early facial exercises may be decrease recovery time and long-term paralysis and chronic cases number [28]. Surgical intervention to free the facial nerve has been considered. However, the evidence for the procedure is of very low quality [29]. Surgical management is divided into management of acute paralysis usually less than 3 weeks of onset, intermediate duration paralysis which is from 3 weeks to 2 years and surgical management of chronic facial paralysis usually with greater than 2 years of onset. Acute management of facial paralysis which includes bell's palsy includes, facial decompression and facial nerve repair [29].

\section{Facial Decompression}

There are 3 approaches for decompression which consist of transmastoid approach which is typically used when the paralysis is clearly involving the tympanic or mastoid segments of the facial nerve.the nerve is decompressed for 180 degrees of its diameter. Another approach is the middle cranial fossa approach which allows decompression in the area of the labyrinthine segment. The third approach is the translabyrinthine approach which could be used to decompress the entire course of the facial nerve intratemporally [30].

\section{Faical Nerve Repair}

Includes primary nerve repair which provides the best return of function to the facial nerve, the primary rapair should be tension free. It's now recommended to perform epineurial repair as suture repair using perineurial and fascicular repair may be difficult and may injure the axon [31]. The intermediate management is for facial parylsis due to acoustic neuroma surgery or surgery in which the facial nerve had low recovery due to stretching, treatment modalities include cross facial grafting and nerve transfers [32].

In chronic management the muscles of facial expression usually will be atrophied and will need the use of donor muscle for reanimation. Therefore, muscle transfer regional or free are the main dynamic reanimation for chronic paralysis [33]. In Regional muscle transfer the temporalis muscle in the most commonly used donor with masseter and digastrics being possible donor sites, in free muscle transfer the most commonly used donors are the gracilis, serratus anterior, lattismus dorsi and pectoralis minor with gracilis muscle being the most commonly used [34].

There is also static technique for facial reanimation which can be used for all durations of facial nerve damage. They enhance the result of facial reanimation or they can also provide an alternative [35]. Techniques used are usually divided into upper eyelid correction and lower eyelid correction. Technique used for upper eyelid include eyelid weight placement, lateral tarsorrhaphy, palpebral spring procedure, upper eyelid blepharoplasty [36]. Techniques used for lower eyelid include lower tarsal strip procedure, medial canthopexy, nasolabial fold modification, static facial suspension, external nasal valvue repair [37].

Another technique is the brow ptosis correction which integral part of management of patient with facial paralysis, which includes a diversity of approaches namely direct brow lift, minimally invasive brow lift and endoscopic brow lift [38]. In sudan a study done by ahmed Hassan kamal and ahmed mohammed sulaiman concluded that the treatment of choice was a combination therapy including mainly steroid therapy vitamin b12 and antiviral agents [3].

\section{Conclusion}

The etiology of bell's palsy is unclear but is known to be due to edema and inflammation of the facial nerve, symptoms range from mild to complete paralysis in severity. Eye management is essential in preventing long term eye complications. Drug therapy is disputable since $70 \%$ of patients will recover normal function without treatment. Early management with corticosteroids can speed recovery and reduce long term complications. There is low quality evidence that supports use of physical therapy in cases with minimal to moderate symptoms and chronic cases. Although the quality of evidence isn't great addition of antiviral agents may be of minimum benefit. It's crucial to discuss the possible pros and cons with patients given the potential adverse effects of prednisolone and antiviral agents use [39].

\section{References}

1. De Diego-Sastre JI, Prim-Espada MP, Fernández-García F (2005) The epidemiology of Bell's palsy. Rev Neurol 41: 287-290.

2. Hauser WA, Karnes WE, Annis J, Kurland LT (1971) Incidence and prognosis of Bell's palsy in the population of Rochester, Minnesota. Mayo Clin Proc 46(4): 258-264.

3. Mustafa A, Sulaiman A (2018) The Epidemiology and Management of Bell's Palsy in the Sudan. The Open Dentistry Journal 12(1): 827-836.

4. Dhruvashree Somasundara (2017) General practitioner and Frank Sullivan, Gordon F Cheesbrough research chair, Director of UTOPIAN FMTU2, Professor3 and Adjunct scientist 40(3): 94-97.

5. Linder T, Bossart W, Bodmer D (2005) Bell's palsy and Herpes simplex virus: fact or mystery? Otol Neurotol 26:109-113.

6. Seok JI, Lee DK, Kim KJ (2008) The usefulness of clinical findings in localising lesions in Bell's palsy: comparison with MRI. J Neurol Neurosurg Psychiatry 79(4): 418-420.

7. Peitersen E (1982) The natural history of Bell's palsy. Am J Otol 4(2): 107-111.

8. Sullivan FM, Swan IR, Donnan PT, Morrison JM, Smith BH, et al. (2009) A randomised controlled trial of the use of aciclovir and/or prednisolone for the early treatment of Bell's palsy: the BELLS study. Health Technol Assess 13: 3-4.

9. Gilden DH (2004) Bell's palsy. N Engl J Med 351: 1323-1331.

10. Hughes GB (1990) Practical management of Bell's palsy. Otolaryngol Head Neck Surg 102(6): 658-663. 
11. Saito O, Aoyagi M, Tojima H, Koike Y (1994) Diagnosis and treatment for Bell's palsy associated with diabetes mellitus. Acta Otolaryngol Suppl 511: 153-155.

12. Sullivan FM, Swan IR, Donnan PT, Morrison JM, Smith BH, et al. (2009) A randomised controlled trial of the use of aciclovir and/or prednisolone for the early treatment of Bell's palsy: the BELLS study. Health Technol Assess 13: 3-4.

13. Madhok VB, Gagyor I, Daly F, Somasundara D, Sullivan M, et al. (2016) Corticosteroids for Bell's palsy (idiopathic facial paralysis). Cochrane Database Syst Rev 7:CD001942.

14. Engstrom M, Berg T, Stjernquist-Desatnik A, Axelsson S, Pitkäranta A, et al. (2008) Prednisolone and valacyclovir in Bell's palsy: A randomized, double-blind, placebo-controlled, multicentre trial. Lancet Neurol 7(11): 993-1000.

15. Dong Y, Yong Z, Ma C, Zhao H (2015) Steroid-antivirals treatment versus steroids alone for the treatment of Bell's palsy: a meta-analysis. Int J Clin Exp Med 8(1): 413-421.

16. Yoo H, Yoon L, Kim H, Kwak M, Park K, et al. (2018) Comparison of conservative therapy and steroid therapy for Bell's palsy in children. Korean Journal of Pediatrics 61(10): 332-337.

17. Goudakos J, Markou K (2009) Corticosteroids vs Corticosteroids Plus Antiviral Agents in the Treatment of Bell Palsy: A Systematic Review and Meta-analysis. Archives of Otolaryngology - Head and Neck Surgery 135(6): 558-564.

18. Pitaro J, Waissbluth S, Daniel S (2012) Do children with Bell's palsy benefit from steroid treatment? A systematic review. International Journal of Pediatric Otorhinolaryngology 76(7): 921-926.

19. Ramsey M, DerSimonian R, Holtel M, Burgess L (2000) Corticosteroid Treatment for Idiopathic Facial Nerve Paralysis: A Meta-analysis. The Laryngoscope 110(3): 335-341.

20. Furuta Y, Takasu T, Sato KC, Fukuda S, Inuyama Y, et al. (1992) Latent herpes simplex virus type 1 in human geninulate ganglia. Acta Neuropathol 84(1): 39-44.

21. Murakami S, Mizobuchi M, Nakashiro Y, Doi T, Hato N, et al. (1996) Bell's palsy and herpes simplex virus: Identification of viral DNA in endoneurial fluid and muscle. Ann Intern Med 124(1): 27-30.

22. De Diego JI, Prim MP, De Sarria MJ, Madero R, Gavilan J (1998) Idiopathic facial paralysis: A randomized, prospective, and controlled study using single-dose prednisone versus acyclovir three times daily. Laryngoscope 108(4-pt1): 573-575.

23. Kawaguchi K, Inamura H, Abe Y, Koshu H, Takashita E, et al. (2007) Reactivation of herpes simplex virus type 1 and varicella-zoster cirus and therapeutic effects of combination therapy with prednisolone and valacyclovir in patients with Bell's palsy. Laryngoscope 117(1): 147 156.
24. De Almeida JR, Al Khabori M, Guyatt GH, Witterick IJ, Lin VY, et al. (2009) Combined corticosteroid and antiviral treatment for Bell palsy: a systematic review and meta-analysis. JAMA 302(9): 985-993.

25. Lee HY, Byun JY, Park MS, Yeo SG (2013) Steroid-antiviral treatment improves the recovery rate in patients with severe Bell's palsy. Am J Med 126(4): 336-341

26. Gronseth GS, Paduga R (2012) American Academy of Neurology Evidence-based guideline update: steroids and antivirals for Bell palsy: report of the Guideline Development Subcommittee of the American Academy of Neurology. Neurology 79: 2209-2213.

27. Allen D, Dunn L (2004) Aciclovir or valaciclovir for Bell's palsy (idiopathic facial paralysis). Cochrane Database Syst Rev 3: CD001869.

28. Teixeira LJ, Valbuza JS, Prado GF (2011) Physical therapy for Bell's palsy (idiopathic facial paralysis). Cochrane Database Syst Rev 7(12): CD006283.

29. McAllister K, Walker D, Donnan PT, Swan I (2013) Surgical interventions for the early management of Bell's palsy. Cochrane Database Syst Rev 16(2): CD007468.

30. Allen D, Dunn L (2004) Aciclovir or valaciclovir for Bell's palsy (idiopathic facial paralysis). Cochrane Database Syst Rev 3: CD001869.

31. Sofferman RA (2005) Facial nerve injury and decompression. In: Nadol JB Jr, Mckenna MJ, editors. Surgery of the ear and temporal bone. Philadelphia (PA): Lippincott Williams and Wilkins pp. 435-450.

32. Humphrey CD, Kriet JD (2008) Nerve repair and cable grafting for facial paral- ysis. Facial Plast Surg 24(2): 170-176.

33. Terzis JK, Konofaos P (2008) Nerve transfers in facial palsy. Facial Plast Surg 24(2): 177-193.

34. Hadlock TA, Cheney ML, McKenna MJ (2005) Facial reanimation surgery. In: Nadol JB Jr, Mckenna MJ, editors. Surgery of the ear and temporal bone. Philadelphia (PA): Lippincott Williams and Wilkins pp. 461-472.

35. Chuang DC (2008) Free tissue transfer for the treatment of facial paralysis. Facial Plast Surg 24(2): 194-203.

36. Liu YM, Sherris DA (2008) Static procedures for the management of the mid- face and lower face. Facial Plast Surg 24(2): 211-215.

37. Bergeron CM, Moe KS (2008) The evaluation and treatment of upper eyelid paralysis. Facial Plast Surg 24(2): 220-230.

38. Chris M Bergeron, Kris S Moe (2008) Technique is the brow ptosis correction which integral part of management of patient with facial paralysis, which includes a diversity of approaches namely direct brow lift, minimally invasive brow lift and endoscopic brow lift. Facial Plast Surg 24(2): 231-241.

39. Meltzer NE, Byrne PJ (2008) Management of the brow in facial paralysis. Facial Plast Surg 24(2): 216-219.

This work is licensed under Creative Commons Attribution 4.0 License DOI: 10.19080/ADOH.2020.12.555850
Your next submission with Juniper Publishers will reach you the below assets

- Quality Editorial service

- Swift Peer Review

- Reprints availability

- E-prints Service

- Manuscript Podcast for convenient understanding

- Global attainment for your research

- Manuscript accessibility in different formats

( Pdf, E-pub, Full Text, Audio)

- Unceasing customer service

Track the below URL for one-step submission https://juniperpublishers.com/online-submission.php 